\title{
¿ERA NECESARIO UN TIPO ESPECÍFICO DE COACCIONES PARA EL DELITO DE MATRIMONIO FORZADO? ANALIZANDO EL ART. 172 BIS DEL CÓDIGO PENAL
}

Marta Pardo Miranda

E-mail: martapardom@gmail.com

RESUMEN: Varios son los interrogantes jurídicos que planteó, y, sigue planteando, la incorporación del delito de matrimonio forzado en el Código penal español en la reforma de 2015 como tipo específico, y diversas las cuestiones doctrinales formuladas al respecto de esta incorporación.

Este estudio se justifica en la necesidad de determinar si fue correcta la respuesta del legislador. Para ello analizo qué debe entenderse por matrimonio forzado, como requisito previo para responder sobre la necesidad de este delito específico y los problemas que puede causar en la interpretación de nuestro ordenamiento jurídico. Llegando a la conclusión, casi unánime en la doctrina, del carácter innecesario del mismo y de la posibilidad de subsunción en otros delitos ya previstos como son los delitos de coacciones o de trata de seres humanos.

PALABRAS CLAVE: Matrimonio forzado, trata de seres humanos, coacciones, amenazas, concurso de delitos.

ABSTRACT: There are several legal questions raised and continues to pose the incorporation of the crime of forced marriage in the Spanish Penal Code in 2015 reform as a specific type, and various doctrinal issues raised in this respect. This study is justified in the need to determine if the response of the legislator was correct.

To this end, I analyze what should be understood by forced marriage, as the prerequisite to answer on the need for this specific crime and the problems it may cause in the interpretation of our legal system. Coming to the conclusion, almost unanimous in the doctrine, of the unnecessary nature of it and the possibility of subsumption in other crimes already planned such as the crimes of coercion or trafficking in human beings.

KEYWORDS: Forced marriage, human trafficking, coercion, threats, concurrent offences.

SUMARIO: I. Introducción. II. Etiología del fenómeno de los matrimonios forzados. III. El concepto de matrimonio forzado. 1. Matrimonios ilegales: 1.1. Matrimonio inválido. 1.2. Matrimonio concertado y matrimonio de conveniencia. 1.3. Matrimonio infantil y precoz. 2. Matrimonio forzado. IV. Evolución legislativa. V. Los distintos tipos del art.172 Bis. 1. El tipo del Artículo 172 bis 1: 1.1. Conducta típica y medios comisivos. 1.2. Sujetos. 1.3. Objeto. 1.4. Culpabilidad. 1.5. Autoría y participación. 1.6. Penas. 2. Breve referencia al tipo del Artículo 172 bis 2 y su relación con el delito de trata de seres humanos. VI. Conclusiones: ¿era necesaria la nueva regalación? 


\section{I.- INTRODUCCIÓN}

No son pocos los problemas que encontramos al abordar la regulación que introdujo el legislador de 2015 en nuestro Código Penal en lo que respecta al delito de matrimonios forzados. Ha sido una cuestión poco debatida, existen pocos datos y la jurisprudencia al respecto es escasa.

No obstante, el delito de matrimonio forzado ha sido objeto de diversas discusiones doctrinales desde su incorporación a nuestro ordenamiento por la LO 1/2015. Algunos autores han analizado cuestiones como su origen legislativo, el tipo y la necesidad de su tipificación.

Sólo el primer apartado del art.172 bis CP requiere de la completa atención de este artículo para un análisis exhaustivo que nos permita entender qué es un matrimonio forzado, cuáles son las causas de los mismos, qué justifica su regulación, qué respuesta ha dado el legislador a este problema, para, finalmente, concluir si ésta ha sido la correcta.

\section{II.- ETIOLOGÍA DEL FENÓMENO DE LOS MATRIMONIOS FORZADOS}

La primera cuestión que surge cuando abordamos el tema del delito de matrimonio forzado es la relativa a qué debe entenderse por matrimonio forzado, pero antes de entrar a analizar esta cuestión es conveniente detenernos sobre cuáles son los problemas que han surgido al respecto y cuál es la etiología de este fenómeno.

Partiendo de las causas del fenómeno, ya surgen varias cuestiones: ¿Éste fenómeno es frecuente en España? ¿Es un problema real? ¿Las cifras justifican la respuesta que les ha dado el legislador?

Puede parecer que el número de matrimonios forzados no es preocupante. Pero ello puede deberse a la vulnerabilidad de los colectivos a los que suele afectar, como son niños y extranjeros, a veces en situación irregular, que desconocen la ley, la cultura y sus propios derechos. Los casos reales que se dan en occidente pueden ser muchos más de los que los datos reflejan.

Como dato relevante señalar que en el año 2014 Unicef estimó que más de 700 millones de mujeres en el mundo contrajeron matrimonio antes de cumplir los 18 años, edad mínima para contraer matrimonio en España. Aunque la proporción de matrimonios forzados en occidente no es clara diversos estudios confirman la realidad del fenómeno en Estados Unidos, en Europa y en otros países occidentales ${ }^{38}$. En España, en 2002, la

38 UNITED NATIONS CHILDREN'S FUND, Ending Child Marriage. Progress and prospects, UNICEF, 
Fiscalía General del Estado difundió una circular preocupada por la «proliferación de este tipo de matrimonios ${ }^{39}$.

Hay escasa información estadística sobre la incidencia real de este problema en nuestro país, y, hasta ahora, ha sido un fenómeno poco conocido. Solo la Comunidad Autónoma de Cataluña y algún estudio empírico reflejan ciertos datos acerca de la frecuencia de los matrimonios forzados, poniendo de manifiesto, en definitiva, que dicha práctica también existe en la realidad española. En esta comunidad desde 2010, la Policía Autonómica impidió ese año 15 matrimonios forzados; en 2011, 21; en 2012, 16; en 2013, 26; en 2014, 10; en 2015, 15; en 2016, 14 y en 2017, $10^{40}$.

Por tanto, es un problema que existe y al que hay que dar respuesta, pero, ¿fue correcta la respuesta que le dio el legislador en 2015?, cuestión principal de este artículo.

Siguiendo con la etiología del delito: ¿Es un problema migratorio, cultural, de honor, religioso, de violencia de género?

Respecto a los motivos que pueden llevar a ejecutar esta conducta son diversos: reforzar los vínculos familiares, asegurar que las riquezas y los bienes permanezcan en el seno familiar, proteger ideales percibidos como culturales o religiosos. En situaciones de migración, ayudar a regularizar la situación administrativa (permisos de residencia y nacionalidad), entre otros ${ }^{41}$.

Si bien, algunos autores han señalado el origen de esta regulación en la incorporación a nuestra realidad de tradiciones propias de otras culturas ${ }^{42}$. Ello no es tan fácil, piénsese que en España se han practicado, por ejemplo, en la etnia gitana, y, se dan otras figuras como los matrimonios de conveniencia que a continuación analizamos.

No es acertado vincular los matrimonios pactados y los matrimonios forzados a una determinada cultura, comunidad o país. En primer lugar, porque no siempre este tipo de matrimonios pueden generalizarse a todo un pueblo, cultura o país, y, en segundo lugar, porque la propia finalidad, forma y características de la institución matrimonial ha evolucionado a lo largo del tiempo. En nuestra propia cultura, encontramos numerosos ejemplos de matri-

New York, 2014.

39 Fiscalía General del Estado, Circular 1/2002, de 19 de febrero, sobre aspectos civiles, penales y contencioso-administrativos de la intervención del fiscal en materia de extranjería. Disponible en: https://www.fiscal.es/fiscal/publico/ciudadano/documentos/circulares_consultas instrucciones.

40 Departament d'Interior, Generalitat de Catalunya disponible en: < $\underline{\text { http://interior.gencat.cat } / \mathrm{ca} / \mathrm{arees}}$ dactuacio/seguretat/violencia-masclista-i-domestica/>

41 VARGAS GALLEGO, A.I., «Sobre los matrimonios forzados», Revista de Jurisprudencia, 2014, vol. 2.

42 CISNEROS ÁVILA, F., «Reflexiones sobre el delito de matrimonio forzado del artículo 172 bis del CP», Diario La Ley, núm. 9072, Sección Tribuna, 2017, Editorial Wolters Kluwer. 
monios pactados o concertados, e incluso de matrimonios forzados, son ejemplos los matrimonios por embarazo, como forma de alianzas familiares o como forma de supervivencia de la mujer en épocas en la que ésta no tenía autosuficiencia económica.

Algunos autores han señalado el problema de los matrimonios forzados como otra manifestación de los delitos de honor, pero, de esta forma se representa como un problema cultural de otras comunidades, donde se necesita la intervención salvadora del estado occidental $^{43}$.

Excepcionalmente se ha considerado contraer matrimonio en el país de origen bajo coacción una forma de violencia de género y se ha reconocido la condición de refugiada a aquellas mujeres que se han escapado a esta coacción en la jurisprudencia española, con posibilidad de solicitar asilo ${ }^{44}$.

Por otro lado, el fenómeno de los matrimonios forzados puede llevar a situaciones de esclavitud o de explotación sexual, muchas veces de menores, como veremos más adelante, ya que la unión matrimonial lleva consigo una serie de «compromisos» que si no se han adquirido con plena voluntad suponen una situación de abuso y sometimiento.

Además, en muchos de los casos, estos «matrimonios» no llegan a constituirse desde el punto de vista formal conforme a la legislación civil de nuestro país, lo que nos lleva a la siguiente cuestión ¿qué debemos entender por matrimonio forzado? ¿Estamos ante un matrimonio?

\section{III.- EL CONCEPTO DE MATRIMONIO FORZADO}

En este punto, la primera cuestión que surge es qué debe entenderse por matrimonio y qué debe entenderse por forzado.

Respeto del matrimonio, tradicionalmente se ha entendido como una institución que ha servido para transmitir las propiedades a las nuevas generaciones y para determinar las responsabilidades hacia los menores de edad. En la sociedad actual, se interpreta que el matrimonio es una institución cuya finalidad es compartir un proyecto de vida en común ${ }^{45}$.

43 IGAREDA GONZÁLEZ, N., «Matrimonios forzados: ¿otra oportunidad para el derecho penal simbólico?», InDret Revista para el análisis del Derecho, 2015, p. 5.

44 Sentencia del Tribunal Supremo (Sala de lo Contencioso-Administrativo) núm. 3155/2006, de 11 de mayo. RJ 4272/2009. Hechos probados: Se considerarse suficientemente acreditado que la actora expuso como causa de su salida de Nigeria la huida frente a un contexto familiar y social en el que se le había obligado a someterse a la bárbara práctica de la ablación genital como paso previo para un matrimonio no deseado. La Sala declara que una situación de desprotección y marginación social, política y jurídica de las mujeres en su país de origen, que vulnere de forma evidente y grave sus derechos humanos, es causa de asilo.

45 IGAREDA, GONZÁLEZ, N. «Debates sobre la autonomía y el consentimiento», Anales de la Cátedra Francisco Suárez, vol. 47, 2013, p. 204. 
El segundo elemento que define el fenómeno objeto de estudio es el relativo a la fuerza. En este aspecto, cabe mencionar que el «alcance, más o menos amplio, que se reconozca al término fuerza y la inclusión en el mismo de formas de presión o abuso psicológico o social, más allá de la violencia estrictamente física, determinarán en qué extensión un matrimonio pueda aceptarse como forzado» ${ }^{46}$.

Ya sobre el término matrimonio surgen varias cuestiones: ¿Los matrimonios forzados que se llevan a cabo en España, cumplen con los requisitos establecidos en la ley para que queden válidamente constituidos? ¿Son matrimonios reconocidos en nuestro ordenamiento jurídico?

No nos atañe hacer aquí un análisis de la regulación del matrimonio en España, cuestión que dejamos al campo del derecho civil, pero no debe pasarse por alto esta institución.

Los cambios acaecidos en nuestra sociedad y, con ello, en nuestra legislación, piénsese por ejemplo en la incorporación del matrimonio entre parejas del mismo sexo, han afectado a la definición del matrimonio.

Si entendemos por matrimonio, de acuerdo a los artículos 49 y 50 C. Civil, la voluntad de convivencia plena «affectio maritalis» manifestada a través del consentimiento, si ésta falta siendo otra la voluntad, podríamos estar ante un matrimonio de conveniencia.

Por otro lado, puede haber consentimiento sin voluntad. En ese caso, no habría un auténtico consentimiento matrimonial, el matrimonio se consideraría nulo de pleno derecho, y, por lo tanto, no estaríamos ante un matrimonio, aunque el legislador utilice la terminología de matrimonio forzado.

No obstante, el contenido del consentimiento matrimonial no está legalmente determinado y ha evolucionado de manera que ya no se puede perfilar el contenido del consentimiento matrimonial fuera de su emisión en la forma requerida por la ley. Siendo así el matrimonio de conveniencia no podría considerarse nulo por falta de consentimiento ${ }^{47}$. Pensemos en la persona que contrae matrimonio por dinero, el ordenamiento no se inmiscuye en la voluntariedad.

Lo que nos lleva a una breve reflexión sobre varias figuras que integran los matrimonios ilegales: matrimonios inválidos, concertados, de conveniencia y precoces, para, finalmente, configurar un concepto de matrimonio forzado.

46 TORRES ROSELL, N., «Matrimonio forzado: aproximación fenomenológica y análisis de los procesos de incriminación», Estudios Penales y Criminológicos, vol. XXXV, 2015, p. 844.

47 TRAPERO BARREALES, M.A., «Matrimonios ilegales y derecho penal. Bigamia, matrimonio inválido, matrimonio de conveniencia, matrimonio forzado y matrimonio precoz», Valencia: Tirant lo Blanch, 2016, p. 
Matrimonios ilegales porque así los denomina el CP, eso sí, para la regulación penal de dos de las modalidades, la bigamia y el matrimonio inválido y porque en todas estas modalidades se trata de la celebración de matrimonios incumpliendo la legislación civil sobre los requisitos para su validez.

\subsection{Matrimonios ilegales}

Los matrimonios ilegales se encuentran regulados en el Título XII, «los delitos contra las relaciones familiares», Capítulo I, «de los matrimonios ilegales», de ello se puede deducir que el legislador trata de proteger una determinada concepción social del matrimonio y tutelar el sistema jurídico matrimonial establecido por el Estado. Estos delitos se constituyen en un refuerzo penal de la tutela de la legislación civil en el ámbito matrimonial ${ }^{48}$.

Como ya he mencionado se trata de la celebración de matrimonios incumpliendo la legislación civil sobre los requisitos para su validez. Son aquellos en los que encontramos causas de nulidad, algunas no convalidables, porque existe un vínculo anterior en uno o los dos contrayentes (bigamia), no hay auténtico consentimiento matrimonial (matrimonio de conveniencia), el consentimiento está viciado porque no se otorga con libertad (matrimonio forzado), uno de los contrayentes no tiene capacidad para consentir por razón de edad (matrimonio precoz) o, genéricamente, concurre alguna de las causas de nulidad del matrimonio, dispensables o no dispensable (matrimonio inválido) ${ }^{49}$.

\subsubsection{Matrimonio inválido}

Lo encontramos regulado en el art. $218 \mathrm{CP}$ con el siguiente tenor literal: «1. El que, para perjudicar al otro contrayente, celebrare matrimonio inválido será castigado con la pena de prisión de seis meses a dos años. 2. El responsable quedará exento de pena si el matrimonio fuese posteriormente convalidado».

El matrimonio inválido es aquel en que concurre alguna de las causas de nulidad del matrimonio, siendo nulo desde su celebración conforme a la legislación civil. Cabe preguntarse: ¿Es el matrimonio forzado un matrimonio inválido?

No todo supuesto de matrimonio nulo conforme a la legislación civil es objeto de atención por el Derecho Penal.

48 CARBOnEll MATEU, J. C. en Derecho penal, parte especial, Valencia, 1996. Pg. 292.

49 TRAPERO BARREALES, M.A., «Matrimonios ilegales y derecho penal. Bigamia, matrimonio inválido, matrimonio de conveniencia, matrimonio forzado y matrimonio precoz». Valencia: Tirant lo Blanch, 2016. p. 18. 
Partiendo de la declaración de nulidad según el CC en ocasiones será preciso añadir determinados requisitos o elementos para configurar el matrimonio nulo o inválido que es objeto de atención por el Derecho Penal.

En el art. $73 \mathrm{CC}$ se define el matrimonio nulo (o inválido): es nulo, cualquiera que sea su forma de celebración: 1) el matrimonio celebrado sin consentimiento matrimonial (en esta causa de nulidad se subsume el matrimonio de conveniencia). 2) El matrimonio celebrado entre personas a que se refieren los arts. 46 y $47 \mathrm{CC}$ (menores no emancipados, los que están ligados con vínculo matrimonial, los parientes en línea recta por consanguinidad o adopción y los colaterales por consanguinidad hasta el tercer grado, los condenados por haber participado en la muerte dolosa del cónyuge o persona con la que hubiera estado unida por análoga relación de afectividad a la conyugal) (en esta causa de nulidad se van a subsumir el matrimonio prematuro, la bigamia, el matrimonio inválido); 3) el que se contraiga sin la intervención del Juez, Alcalde o funcionario ante quien deba celebrarse, o sin la de los testigos (en esta causa de nulidad se subsume el matrimonio inválido); 4) el celebrado por error en la identidad de la persona del otro contrayente o en aquellas cualidades personales que, por su entidad, hubieren sido determinantes de la prestación del consentimiento (en esta causa de nulidad se subsume el matrimonio inválido); y, finalmente, 5) el contraído por coacción o miedo grave (dependiendo de quién provoque la coacción o el miedo, en esta causa de nulidad se subsume el matrimonio forzado o el matrimonio inválido) ${ }^{50}$.

Como vemos, el matrimonio forzado, se contrae por coacción y, conforme, a la legislación civil es un matrimonio nulo. Pero, ¿todos los matrimonios forzados se contraen por coacción?, entiendo que sí, la coacción es un presupuesto de este delito.

\subsubsection{Matrimonio concertado y matrimonio de conveniencia}

Es necesario distinguir el matrimonio forzoso del llamado matrimonio concertado o acordado, piénsese en el caso en el que las dos partes consienten a sus padres, a un consejo familiar o comunitario o a una tercera persona la elección del esposo o esposa, aceptando luego ese vínculo voluntariamente. Costumbre europea hasta principios del siglo XX, con una gran importancia social y económica, en particular a raíz de la dote. Hasta el siglo XIX no se instalaría en la cultura occidental el concepto de la libre elección del propio cónyuge.

Puede ofrecer cierta dificultad la tarea de diferenciar entre matrimonios simplemente pactados y matrimonios forzados, dado que los segundos generalmente fueron en

50 TRAPERO BARREALES, M.A., «Matrimonios ilegales y derecho penal. Bigamia, matrimonio inválido, matrimonio de conveniencia, matrimonio forzado y matrimonio precoz». Valencia: Tirant lo Blanch, 2016. p. 3. 
sus inicios también pactados, pero, ¿Quién los pacta? La diferencia está en la coacción de una de las partes. Igualmente, no debe confundirse el matrimonio forzado con el denominado «de conveniencia», aunque este último también pueda revestir carácter ilícito por celebrarse en fraude de ley ${ }^{51}$.

Entendiendo el matrimonio como la unión de dos personas a través del cumplimiento de determinados ritos o formalidades $y$, aunque, en la actualidad ya no se deduce de la regulación legal de la institución, la definición se complementa con la finalidad de constituir una vida en común entre los contrayentes, si esa finalidad está ausente estamos ante el matrimonio de conveniencia, o también denominado matrimonio blanco, una modalidad de los denominados genéricamente matrimonios simulados.

La falta de intención de asumir los derechos y obligaciones que surgen de la celebración de este negocio jurídico (plasmados en los arts. 67 y $68 \mathrm{CC}$ ) tiene como consecuencia que no haya un auténtico consentimiento matrimonial, elemento esencial que ha de concurrir para la constitución de esta unión por lo que, faltando tal elemento, el matrimonio celebrado de esta manera es nulo de pleno derecho ${ }^{52}$.

Por tanto, hay una línea muy estrecha entre matrimonio forzado y matrimonio concertado. El matrimonio concertado puede ser o no forzado. La diferencia entre uno y otro vendrá marcada por la voluntariedad del consentimiento.

En el matrimonio concertado las familias de los contrayentes tienen un papel relevante, al ser ellos los que pactan la celebración de la unión matrimonial. Los contrayentes prestarán un consentimiento más o menos influenciados, presionados por sus familias, pero finalmente no se van a oponer a la unión, por tanto, van a emitir el consentimiento matrimonial de manera válida y eficaz. No sucede lo mismo con el matrimonio forzado, como veremos ${ }^{53}$.

A pesar de lo señalado el matrimonio de conveniencia o complacencia sigue considerándose un matrimonio nulo por falta de consentimiento matrimonial. Y es objeto de preocupación y atención en un supuesto muy particular, cuando en el matrimonio concurre

51 ESQUINAS VALVERDE, P., «El delito de matrimonio forzado (art. 172 bis CP) y sus relaciones concursales con otros tipos delictivos», Revista Electrónica de Ciencia Penal y Criminología. 2018, núm. 20-32, p. 1-47.

52 CARRASCOSA GONZÁLEZ, J., «Las crisis matrimoniales en el derecho internacional privado» en: Yzquierdo Tolsada/Cuena Casas (dirs.), Tratado de Derecho de Familia I. Derecho de familia y Derecho de la familia. La relación jurídico-familiar. El matrimonio y su celebración, Aranzadi Thomson-Reuters, Cizur Menor (Navarra), 2011, p. 1054.

53 TRAPERO BARREALES, M.A., «Matrimonios ilegales y derecho penal. Bigamia, matrimonio inválido, matrimonio de conveniencia, matrimonio forzado y matrimonio precoz». Valencia: Tirant lo Blanch, 2016. p. 4. 
un factor de extranjería. En efecto, el motivo más habitual que está detrás de esta unión o, al menos, el motivo que más preocupa a las autoridades que han de controlar y evitar la inscripción de un matrimonio de estas características en el Registro Civil, es el fin de regularizar la situación administrativa en el país de uno de los contrayentes. Difícilmente se puede pensar que en este caso el bien jurídico protegido sea la institución del matrimonio.

Para evitar este tipo de matrimonios se han producido cambios normativos tanto a nivel estatal, como dentro del ámbito europeo como la Resolución del Consejo de las Comunidades Europeas de 4 diciembre 1997. ${ }^{54}$.

Muchos de estos matrimonios afectan a menores de edad, lo que constituye otra modalidad de matrimonio, el matrimonio infantil o precoz.

\subsubsection{Matrimonio infantil y precoz}

El matrimonio infantil es aquel en el que al menos uno de los contrayentes es un niño. De conformidad con la Convención sobre los Derechos del Niño de 20 de noviembre de 1989, «se entiende por niño todo ser humano menor de 18 años de edad, salvo que, en virtud de la ley que le sea aplicable, haya alcanzado antes la mayoría de edad». Otro término que se usa como sinónimo de «matrimonio infantil» es el de «matrimonio precoz»y y se refiere a los matrimonios en los que uno de los contrayentes es menor de 18 años en países en los que la mayoría de edad se alcanza más temprano o tras el matrimonio. El matrimonio precoz también puede referirse a matrimonios en los que ambos contrayentes tienen por lo menos 18 años, pero otros factores determinan que no están preparados para consentir en contraerlo. Se entiende que el matrimonio infantil es una modalidad de matrimonio forzado, ya que cuando, por lo menos, uno de los contrayentes es menor de edad el consentimiento eventualmente prestado no se puede considerar suficientemente pleno y libre. El matrimonio infantil se identifica con el matrimonio forzado en numerosos textos internacionales, fundamentalmente de Naciones Unidas ${ }^{55}$.

ABAD ARENAS define el matrimonio forzado como aquel en el que falta el libre y válido consentimiento de alguno de los contrayentes, mientras que el matrimonio precoz es el contraído por un menor de 18 años. Partiendo de estas definiciones, para esta autora, «los matrimonios forzosos se equiparán a los precoces, en los supuestos en los que el enlace matrimonial se realiza con menores, conculcan el libre consentimiento de los contrayentes, y omiten el requisito de edad $\rangle^{56}$.

54 VARGAS GALLEGO, A.I. «Sobre los matrimonios forzados» Revista de Jurisprudencia, $N^{\circ}$ 2, 2014. p. 3.

55 Asamblea General de Naciones Unidas. Informe de la Oficina del Alto Comisionado de las Naciones Unidas, 2014, p. 3-4.

56 ABAD ARENAS, E., «Libertad matrimonial y matrimonios forzados», Diario La Ley, $\mathrm{N}^{\circ} 8288$, Sección Doctrina, 2014, Editorial LA LEY, p. 7. 
El informe de la Oficina del Alto Comisionado de las Naciones Unidas para los Derechos Humanos del 2 de abril de 2014 aborda la cuestión de las medidas y estrategias para prevenirlo y eliminarlos como elevar la edad mínima para contraer matrimonio a los 18 años o aplicar el registro obligatorio de los matrimonios. Sin embargo, en el Informe no se defiende la penalización de los matrimonios forzados ${ }^{57}$.

El Derecho Penal sí tiene respuesta frente éste: Se puede recurrir al delito de matrimonio inválido, art. $218 \mathrm{CP}$, si el contrayente actúa con intención de perjudicar al otro contrayente menor de edad. El problema es que el perjuicio se ha planteado como un especial elemento subjetivo del injusto y requiere la intención en el contrayente de perjudicar al otro. Cuando se celebra un matrimonio precoz el contrayente mayor de edad puede ser consciente de los posibles efectos negativos para el otro cónyuge menor, pero no contrae matrimonio con intención perjudicarle.

También, se puede recurrir al delito de matrimonio forzado prematuro o precoz. Esta es la figura delictiva tipificada en el art. 172 bis.3 CP: "Las penas se impondrán en su mitad superior cuando la víctima fuera menor de edad». Estamos en presencia de un tipo cualificado del delito de matrimonio forzado, cualificación basada en la minoría de edad de la víctima. Es decir, es necesario que se recurra a la intimidación grave o a la violencia para obligar al menor a contraer matrimonio, en la primera de las modalidades típicas, o es necesario recurrir a la intimidación grave, violencia, engaño, para lograr que la víctima abandone el país para posteriormente obligarla a contraer matrimonio, o para lograr que la víctima no regrese al país porque va a ser obligada a contraer matrimonio, en la segunda de las modalidades típicas.

Debemos tener en cuenta que tratándose de edades muy tempranas no será necesario el recurso a la intimidación o a la violencia, pues el menor a esa edad no entenderá qué significa la celebración del matrimonio, y no pondrá obstáculo a su celebración. En estos supuestos se estará en el campo específico del matrimonio prematuro, supuesto que queda fuera del ámbito penal.

En tercer lugar, para la prevención penal del matrimonio prematuro o precoz puede recurrirse al delito de trata de personas del art. 177 bis $\mathrm{CP}$, que abordamos más tarde.

En el delito de trata de personas se ofrece un tratamiento específico para cuando la víctima sea menor de edad: en este caso se considerará trata de personas cualquiera de las acciones que se han tipificado penalmente con finalidad de explotación del menor aunque

57 Asamblea General de Naciones Unidas. Informe de la Oficina del Alto Comisionado de las Naciones Unidas, 2014 p. 10-15. 
se lleven a cabo sin el recurso a ninguno de estos medios comisivos. Pero tampoco el delito de trata de personas da respuesta a todos los supuestos de matrimonios prematuros.

En primer lugar, es preciso que el matrimonio prematuro se subsuma en alguna de las conductas típicas dirigidas a la explotación de las personas que definen el delito de trata de personas. En segundo lugar, para el caso de que se esté en presencia de una de estas conductas con fines de explotación características de la trata, tal aplicación está condicionada a que se esté ante la celebración de un matrimonio forzado. Si para la interpretación de esta finalidad se está a la definición de matrimonio forzado del art. 172 bis $\mathrm{CP}$, en tal caso nuevamente se tendrá respuesta penal frente al matrimonio forzado prematuro, pero no para el matrimonio prematuro o precoz. Quizás a través del análisis del delito de trata de personas se puede evidenciar una laguna de punibilidad.

Lo que podría resolverse incluyendo como finalidad la celebración de matrimonios forzados o prematuros ${ }^{58}$.

\subsection{Matrimonio forzado}

El delito de matrimonio forzado ha sido objeto de diversas discusiones doctrinales, el origen de esta regulación trae causa en los derechos reconocimos en las diversas constituciones y en los textos internacionales. En nuestra Constitución el Art.32 declara que «El hombre y la mujer tienen derecho a contraer matrimonio con plena igualdad jurídica ${ }^{59}$. Por su parte, el Artículo 16 de la Declaración Universal de los Derechos Humanos establece el derecho a elegir y aceptar libremente el matrimonio ${ }^{60}$. Por su parte, el art. 16 del Convenio para la eliminación de todas las formas de discriminación contra la mujer exige la adopción de medidas para la eliminación de la discriminación de la mujer en asuntos relacionados con el matrimonio y las relaciones familiares, en particular, se exige el aseguramiento en condiciones de igualdad entre hombres y mujeres a) el mismo derecho para contraer matrimonio; b) el mismo derecho para elegir libremente cónyuge y contraer matrimonio solo por su libre albedrío y su pleno consentimiento ${ }^{61}$.

En cuanto al concepto jurídico-internacional de matrimonio forzado, de acuerdo con ACNUR, éste se caracteriza porque en él una de las dos partes se casa en contra de su

58 TRAPERO BARREALES, M.A., «Matrimonios ilegales y derecho penal. Bigamia, matrimonio inválido, matrimonio de conveniencia, matrimonio forzado y matrimonio precoz». Valencia: Tirant lo Blanch, 2016. P. 15.

59 España. Constitución. «BOE» núm. 311, de 29 de diciembre de 1978, páginas 29313 a 29424.

60 Declaración Universal de los Derechos Humanos, Adoptada y proclamada por la Asamblea General en su resolución 217 A (III), de 10 de diciembre de 1948. Disponible en: https://dudh.es/.

61 Convención sobre la eliminación de todas las formas de discriminación contra la mujer. Adoptada y abierta a la firma y ratificación, o adhesión, por la Asamblea General en su resolución 34/180, de 18 de 
voluntad o a la fuerza. Los mismos rasgos esenciales contempla la definición aportada por la Oficina del Alto Comisionado para las NU en su informe, anteriormente mencionado, de 2014, según el cual es forzado todo aquel matrimonio «que se celebra sin el consentimiento pleno y libre de al menos uno de los contrayentes y/o cuando uno de ellos o ambos carecen de la capacidad de separarse o de poner fin a la unión, entre otros motivos debido a coacciones o a una intensa presión social o familiar» ${ }^{62}$.

De esta definición debemos analizar varias cuestiones: Por un lado, la expresión «al menos una» nos indica que basta con que el consentimiento de uno de los contrayentes no haya sido prestado libremente, pero, también, que pueden darse matrimonios forzados en que el sujeto pasivo sean ambos contrayentes.

En cuanto al término «celebración», el Artículo 49 del Código civil dispone que «cualquier español podrá contraer matrimonio dentro o fuera de España: 1. 'Ante el Juez, Alcalde o funcionario señalado por este Código. 2. ${ }^{o}$ En la forma religiosa legalmente prevista. También podrá contraer matrimonio fuera de España con arreglo a la forma establecida por la ley del lugar de celebración».

Para definir el matrimonio forzado deben tenerse en cuenta los requisitos formales exigidos para su celebración. Si el matrimonio no es contraído en alguna de estas formas no esteremos ante un matrimonio, y, entiendo, el legislador, no debería enmarcas este tipo de conductas dentro del término matrimonio.

Para determinar qué es un matrimonio forzado, debemos saber qué se entiende por consentimiento y qué es la libertad.

En cuanto al «consentimiento», el artículo 45 del Código Civil dispone que «no hay matrimonio sin consentimiento matrimonial». Por consentimiento matrimonial se entiende la necesaria concordancia o equivalencia entre las dos declaraciones de voluntad, expresadas por ambos cónyuges, de querer contraer matrimonio, como tal negocio jurídico. CC

El término «querer» introduce otro elemento, la voluntariedad del consentimiento. En este sentido, la doctrina civilista ha puesto de relieve que la reforma de $\mathrm{CC}$ en el año 2005 en materia de separación y divorcio ha podido afectar a la concepción del consentimiento matrimonial. En la actualidad es difícil precisar en qué consiste el consentimiento matrimonial fuera o más allá de su emisión en la forma requerida por la ley. Se llega a afirmar que, tras la reforma al aceptarse su carácter unilateral y acausal, ya no existe razón

diciembre de 1979. Disponible en: $\leq$ https://www.ohchr.org/sp/professionalinterest/pages/cedaw.aspx $>$

62 ESQUINAS VALVERDE, P., «El delito de matrimonio forzado (art. 172 bis CP) y sus relaciones concursales con otros tipos delictivos», Revista Electrónica de Ciencia Penal y Criminología. 2018, núm. 20-32, p. 4. 
para mantener que el consentimiento matrimonial haya de referirse a los deberes conyugales y, en consecuencia, su exclusión no puede ser motivo de nulidad del matrimonio.

PABLO CONTRERAS señala que no tiene un contenido sustantivo, por lo que la comprobación de su concurrencia solo puede realizarse desde la perspectiva de los requisitos para declarar la validez del consentimiento, formal o externamente referido a la celebración del matrimonio ${ }^{63}$.

Por lo que se refiere al término «libertad», la peculiaridad del matrimonio forzado es que falta la libertad de uno o de los dos contrayentes en su celebración, ¿Es libre la persona que acepta el matrimonio por presiones familiares? Entiendo que para que no exista tal libertad es necesaria una oposición de uno de los contrayentes y, posteriormente, una doblegación de la misma, recurriendo para ello a la coacción, la amenaza, la violencia física o la privación de libertad (delitos ya tipificados) ${ }^{64}$.

Respecto a la definición de matrimonio infantil, tampoco sirve para enmarcar el problema que nos ocupa, pues no puede presumirse que se está ejerciendo fuerza o coacción para que se lleve a cabo por el hecho de que uno de los contrayentes sea menor de 18 años.

Sumando estos elementos la doctrina ha definido el matrimonio forzado como aquel celebrado entre dos personas en que al menos una de ellas está coaccionada o amenazada. No obstante, la tipificación expresa en el ámbito penal de los matrimonios forzados ha sido recibida con división de opiniones, entre quienes están a favor de la regulación penal y quienes denuncian la incorrección técnica.

\section{IV.- EVOLUCIÓN LEGISLATIVA}

En la legislación de este tipo penal destacan dos vías desde las que se ha venido abordando la cuestión: la que lo vincula con la violencia doméstica y de género, y la que lo contempla como una forma de esclavitud unida a la trata de seres humanos.

Desde el punto de vista del Derecho Internacional, el matrimonio no empezó a ser regulado hasta la segunda mitad del siglo $\mathrm{XX}$, en algunos de los primeros tratados que aprobaron las Naciones Unidas:

63 DE PABLO CONTRERAS, P., «Matrimonio civil y sistema matrimonial», en: Yzquierdo Tolsada/ Cuena Casas (dirs.), Tratado de Derecho de Familia I. Derecho de familia y Derecho de la familia. La relación jurídico-familiar. El matrimonio y su celebración, Aranzadi Thomson-Reuters, Cizur Menor (Navarra), 2011, 514 ss.

64 TRAPERO BARREALES, M.A., «Matrimonios ilegales y derecho penal. Bigamia, matrimonio inválido, matrimonio de conveniencia, matrimonio forzado y matrimonio precoz». Valencia: Tirant lo Blanch, 2016, p. 7. 
El art. 16.1 de la Declaración Universal de Derechos Humanos (1948) —EDL 1948/48 - proclamó que «Los hombres y las mujeres, a partir de la edad núbil, tienen derecho, sin restricción alguna por motivos de raza, nacionalidad o religión, a casarse y fundar una familia, y disfrutarán de iguales derechos (...)». A continuación, el tercer párrafo remarcó que «La familia es el elemento natural y fundamental de la sociedad y tiene derecho a la protección de la sociedad y del Estado» ${ }^{65}$.

Unos años más tarde, el art. 23.2 del Pacto Internacional de Derechos Civiles y Políticos de 1966 reconoció el derecho del hombre y de la mujer a contraer matrimonio y a fundar una familia si tienen edad para ello $^{66}$.

Ese mismo año, el art. 10.1 in fine del Pacto Internacional de Derechos Económicos, Sociales y Culturales estableció que El matrimonio debe contraerse con el libre consentimiento de los futuros cónyuges ${ }^{67}$.

Ubicado en una violación de los derechos Fundamentales, y, en concreto, en los Derechos de las mujeres, una de las más importantes de estas normas es la Convención sobre la Eliminación de todas las Formas de Discriminación contra las Mujeres adoptada por la Asamblea General de Naciones Unidas en el $1979^{68}$.

En España hasta la entrada en vigor de la LO 1/2015 no existían leyes que regularan la conducta de los matrimonios forzados. No obstante, podían ser subsumidos en diferentes tipos penales, como veremos a continuación.

La tipificación de un nuevo delito de matrimonio forzado, responde, según la exposición de motivos de la ley de 2015, al cumplimiento con los compromisos internacionales suscritos por España en lo relativo a la persecución de los delitos que atentan contra los derechos humanos ${ }^{69}$.

65 Declaración Universal de los Derechos Humanos, Adoptada y proclamada por la Asamblea General en su resolución 217 A (III), de 10 de diciembre de 1948. Disponible en: https://dudh.es/.

66 Pacto Internacional de Derechos Civiles y Políticos, Adoptado y abierto a la firma, ratificación y adhesión por la Asamblea General en su resolución 2200 A (XXI), de 16 de diciembre de 1966. (EDL 1977/998). Disponible en: <https://www.ohchr.org/sp/professionalinterest/pages/ccpr.aspx>

67 Pacto Internacional de Derechos Económicos, Sociales y Culturales, Adoptado y abierto a la firma, ratificación y adhesión por la Asamblea General en su resolución 2200 A (XXI), de 16 de diciembre de 1966. (EDL 1977/997). Disponible en: < $\underline{\text { https://www.ohchr.org/sP/Professionalinterest/Pages/ }}$ cescr.aspx $>$

68 Convención sobre la eliminación de todas las formas de discriminación contra la mujer, Adoptada y abierta a la firma y ratificación, o adhesión, por la Asamblea General en su resolución 34/180, de 18 de diciembre de 1979. (EDL 1983/9186). Disponible en: <https://www.ohchr.org/sp/professionalinterest/ pages/cedaw.aspx $>$

69 España. Ley Orgánica 1/2015, de 30 de marzo, por la que se modifica la Ley Orgánica 10/1995, de 23 de noviembre, del Código Penal. (BOE» núm. 77, 31-3-2015). 
Otro instrumento internacional al que se refiere el preámbulo de la ley es la Directiva 2011/36/ UE del Parlamento Europeo y del Consejo, de 5 de abril de 2011, relativa a la prevención y la lucha contra la trata de seres humanos y a la protección de las víctimas. Esta Directiva insta a los legisladores europeos a adoptar las medidas necesarias para que sean punibles aquellas conductas que puedan dar lugar a la explotación de seres humanos, situando los matrimonios forzados como uno de los supuestos que puede convertirse en una finalidad de la trata.

Esto llevó a introducir en la reforma de 2015 los matrimonios forzados en el art.177 bis del CP como una de las finalidades de explotación de seres humanos. Sin embargo, como veremos en este artículo, no parece que de esta norma europea se pueda deducir la existencia de un mandato de incriminación de los matrimonios forzados ${ }^{70}$.

Vemos como la citada directiva no obliga a la tipificación expresa, como delito, del matrimonio forzado, sino a que se consideren delictivas las conductas de trata de seres humanos ${ }^{71}$.

Es discutible la necesidad de tipificación de estas conductas porque los tipos genéricos de amenazas o de coacciones ya cubrían las conductas que ahora se tipifican.

No obstante, la postura del CGPJ es otra, en cuyo informe se muestra a favor de la intervención con el argumento de que la situación actual que obliga a sancionar por las conductas típicas de coacciones, detenciones ilegales, contra la libertad sexual, etc., que, efectivamente, se hayan producido, no ofrecía una satisfactoria protección del bien jurídico lesionado ${ }^{72}$.

La Convención sobre la eliminación de todas las formas de discriminación contra la mujer de Naciones Unidas en su artículo 16 obliga a los Estados parte a adoptar medidas para eliminar la discriminación contra la mujer y reconoce el derecho a contraer matrimonio con igualdad $^{73}$.

70 GUINARTE CABADA, G., «El nuevo delito de matrimonio forzado» en GONZÁLEZ CUSSAC (dir.) Comentarios a la reforma del Código Penal de 2015.Valencia: Tirant lo Blanch, 2015, p.562.

71 DEL ROSAL BLASCO, B., «Delitos contra la libertad» en: Lorenzo Morillas Cueva (dir) Sistema de Derecho Penal. Parte Especial. Dykinson, S.L., 2015, p. 175.

72 Consejo General del Poder Judicial: Comisión de estudios e informes. Informe al Anteproyecto de Ley Orgánica por la que se modifica la Ley Orgánica 10/1995, de 23 de noviembre, del Código Penal. Disponible en: http://www.poderjudicial.es/cgpj/es/Poder-Judicial/Consejo-General-del-PoderJudicial/Actividad-del-CGPJ/Informes/Informe-al-anteproyecto-de-Ley-Organica-por-el-que--semodifica-la-Ley-Organica-10-1995--de-23-de-noviembre--del-Codigo-Penal

73 Convención sobre la eliminación de todas las formas de discriminación contra la mujer, Adoptada y abierta a la firma y ratificación, o adhesión, por la Asamblea General en su resolución 34/180, de 18 de diciembre de 1979. (EDL 1983/9186). Disponible en: < $\underline{\text { https://www.ohchr.org/sp/professionalinterest/ }}$ pages/cedaw.aspx $>$ 
Pero entienden, algunos autores, que este argumento es erróneo ya que, con él, se protege un derecho y no un valor que oriente teleológicamente la norma ${ }^{74}$.

Finalmente, debo señalar la influencia de los países de nuestro entorno, siendo Noruega el primer país en incorporar el delito de matrimonio forzado a su ordenamiento en el año 2003. Le seguirían Alemania en 2005, Austria en 2006, Francia en 2010 y Holanda en 2013. Cabe destacar que Gran Bretaña lleva a cabo un plan de acción conjunto entre el Home office y la Foreign and Commonwealth Officce para afrontar la dimensión internacional del matrimonio forzado. Dando lugar a la aprobación de la Anti-social Behaviour Crime and Policing Act 2014, que supuso la incorporación al CP inglés del delito de matrimonio forzado. En cabio, en países como Italia no ha sido incorporado, se ha subsumido en otros tipos como el delito de violencia privada (art. 610) ${ }^{75}$.

\section{V.- LOS DISTINTOS TIPOS DEL ARTÍCULO 172 BIS}

Bajo la estructura típica de las coacciones se prevén dos delitos distintos, en atención a la concreta capacidad de obrar lesionada pero conectados en una relación medio (Forzar a abandonar el territorio) fin (Para forzar a contraer matrimonio), así como un subtipo agravado a cada uno de ellos. Encontramos dos modalidades: el delito de matrimonio forzado (art. 172 bis 1); el delito de forzamiento a abandonar o impedir regresar a territorio español (art. 172 bis 2) y un subtipo agravado cuando la víctima sea menor de edad (art. 172 bis 3$)$.

\subsection{El tipo del Artículo 172 bis 1}

\subsubsection{Conducta típica y medios comisivos}

El apartado primero del art.172 bis CP sanciona a quien «con intimidación grave o violencia compela a otra persona a contraer matrimonio». Estamos ante una modalidad de coacciones en la que el sujeto pasivo es obligado a hacer algo, en este caso, contraer matrimonio, contra su voluntad. Delito común, en el que el sujeto activo puede ser cualquier persona ${ }^{76}$.

74 MUÑOZ CUESTA, J., «Cuestiones prácticas sobre la reforma penal de 2015», Navarra, Aranzadi, 2015, pp. 128 y ss.

75 BRIONES MARTÍNEZ, I.M., «Los matrimonios Forzados en Europa. Especial referencia a Francia, Dinamarca, el Reino Unido, Alemania y Noruega», Revista general de derecho canónico y derecho Eclesiástico del Estado, vol. 20, 2009.

76 CISNEROS ÁVILA, F., «Reflexiones sobre el delito de matrimonio forzado del artículo 172 bis del CP», Diario La Ley, N 9072, Sección Tribuna, 2017, Editorial Wolters Kluwer. 
Como ya he señalado, dada su ubicación, el precepto se configura como un tipo específico de coacciones en su modalidad de compeler a otro a efectuar lo que no quiere. Algunos autores entienden que no exige que se produzca el resultado pretendido, de manera que la eventual celebración del matrimonio formaría parte del agotamiento del delito, el cual de conformidad a los artículos 45 y 73 del C. Civil, sería nulo por falta de consentimiento. Por ello, en tanto que tiene la misma penalidad que el tipo básico de coacciones del art. 172.1, su utilidad ha sido discutida por la doctrina. En cualquier caso, el matrimonio forzado debe presentarse como inminente al tiempo de producirse los actos de grave intimidación o violencia.

Por el contrario, GUINARTE CABADA señala que teniendo en cuenta el artículo 61 del Código Civil que establece que «el matrimonio produce efectos desde su celebración», la consumación se producirá cuando la persona compelida haya contraído el matrimonio y no con el simple ejercicio de la violencia o intimidación que no consiga su propósito $^{77}$.

En cuanto al elemento normativo, el matrimonio, habrá que tener en cuenta la regulación del matrimonio civil en España, abarcando cualquier matrimonio reconocido por la legislación española (Arts. 49 y 50 del C.Civil). En contra, DE LA CUESTA AGUADO entiende que no nos encontramos ante un elemento normativo del tipo sino descriptivo ${ }^{78}$.

Respecto a qué debe entenderse por «consumación» de un delito nuestro Código Penal debe estarse siguiendo a RODRÍGUEZ MOURULLO a la realización de todos los elementos que en parte especial se señalan al tipo. En este caso compeler a otra persona a contraer matrimonio.

Siguiendo a GUINARTE CABADA entiendo que el matrimonio es condición, siendo forzado es un matrimonio nulo, por lo que no podemos considerarlo resultado.

Ahora bien, no se requiere que el matrimonio haya de considerarse válido ni que se haya producido su inscripción en el Registro Civil español, o equivalente, sino que basta con que se haya celebrado con apariencia de licitud. Si se hubiese contraído en territorio español, sería nulo en virtud del artículo 73 del CC. Así pues, se desprende que el delito de matrimonio forzado es un delito de resultado, en tanto que hasta que no se contrae el matrimonio no se consuma el delito.

77 GUINARTE CABADA, G., «El nuevo delito de matrimonio forzado» en GONZÁLEZ CUSSAC (dir.) Comentarios a la reforma del Código Penal de 2015.Valencia: Tirant lo Blanch, 2015. p.563.

78 DE LA CUESTA AGUADO, P.M., «El delito de matrimonio forzado» en QUINTERO OLIVARES, Gonzalo (dir.). Comentario a la reforma penal de 2015. Navarra: Aranzadi, 2015. pp. 300 ss. 
El delito del Art.172 bis es un delito de medios determinados pues requiere para la realización de la conducta típica la concurrencia de la intimidación grave o de la violencia.

QUINTERO OLIVARES destaca que la previsión de medios comisivos del art.172 bis es más amplia que la del tipo básico de cocciones, dado que junto a la violencia incluye también la intimidación grave. Respondiendo a la realidad en la que acontece este delito, donde la presión familiar hace innecesaria la violencia física.

En este punto ¿Cabe la tentativa en este tipo? Es diferente la respuesta según el momento en que se entienda consumado el delito.

Para los que entienden que el delito se consuma con la simple manifestación de la voluntad matrimonial forzada no cabría tentativa, ya que los actos de intimidación grave o violencia serían en sí constitutivos de un delito de matrimonio forzado.

En mi opinión siendo necesaria la celebración del matrimonio forzado para que el delito se entendiera consumado cabe la tentativa si concurre la violencia e intimidación destinadas a forzar el consentimiento matrimonial, pero el matrimonio no se celebra finalmente.

\subsubsection{Sujetos}

Respecto a los sujetos de este delito, el art.172 bis se configura como delito común sin que el tipo requiera especiales condiciones del sujeto activo. Lo serán tanto la persona que obliga a celebrarlo, como un tercero ajeno a la relación matrimonial interesado en que se produzca. Incluso un tercero de buena fe.

En relación con el sujeto pasivo, téngase presente que el sujeto pasivo puede ser hombre o mujer. Sin obviar que las cifras aportadas por organismos internacionales indican una mayor prevalencia del fenómeno entre las mujeres y niñas ${ }^{79}$.

\subsubsection{Objeto}

El objeto del delito es la realidad sobre la que recae la acción típica. Considerada en su realidad física hablamos de objeto material del delito, considerada en su valor jurídico, hablamos de bien jurídico protegido ${ }^{80}$. Como señala Mir Puig, el derecho penal ha de justificarse, en tanto sistema de protección de la sociedad. En un Estado social y

79 Asamblea General de Naciones Unidas. Informe de la Oficina del Alto Comisionado de las Naciones Unidas para los Derechos Humanos sobre Prevención y eliminación del matrimonio infantil, precoz y forzado, 2014.

80 LUZÓN CUESTA, J.M. «Compendio de Derecho Penal», Dykinson, S.L., 2015, p. 61. 
democrático, solo deberá amparar como bienes jurídicos condiciones fundamentales de la vida social ${ }^{81}$.

El art.172 bis 1 del Código Penal se sitúa en el capítulo III «coacciones» del título VI «delitos contra la libertad». Esta ubicación conlleva que el objeto de protección sea la libertad de obrar de las personas, en este caso la libertad de una persona para decidir si contraer matrimonio o no ${ }^{82}$. Es este punto cabe preguntarse: ¿El bien jurídico de este delito alcanza la fase de formación de la voluntad o sólo afecta al momento de ejecución de la propia decisión?

Doctrinalmente la distinción entre amenazas y coacciones se ha llevado a cabo con el criterio temporal. Para entender que el delito es de amenazas debe darse un aplazamiento temporal del mal augurado, en cambio en las coacciones el mal se presenta como inminente y actual. ${ }^{83}$

Si entendemos que este delito afecta particularmente al derecho a la formación de la voluntad, se desplazaría el bien jurídico a un momento ubicado en el interior del intelecto. En opinión de QUINTERO OLIVARES se refiere a la libertad de expresión y ejecución de las propias decisiones y actos. Si el objeto de ataque se adelanta a la fase de formación de la voluntad se invadiría el espacio propio de las amenazas, por tanto, el elemento caracterizador de las coacciones, entiende este autor, es la violencia inmediata. Otro sector de la doctrina entiende que parece necesario admitir que el bien jurídico alcanza el proceso de formación de la voluntad ${ }^{84}$.

Entiendo que el artículo 172 bis CP es una modalidad de coacción cuyo bien jurídico es la libertad de ejecutar las decisiones previamente adoptadas, es decir, ejecutar lo ya decidido y no la libertad en el proceso de toma de la decisión. Ya que el sujeto pasivo es libre en adoptar una decisión, pero no en ejecutarla.

\subsubsection{Culpabilidad}

En cuanto al tipo subjetivo del injusto, no ofrece dificultades de delimitación. Estamos ante un tipo doloso en el que concurren los dos elementos: intelictivo, representación y conocimiento del hecho, y, volitivo, voluntad de ejecutar el hecho. Siguiendo a

81 LUZÓN CUESTA, J.M. «Compendio de Derecho Penal», Dykinson, S.L. 2015, p. 33.

82 MUÑOZ CUESTA, J., «Cuestiones prácticas sobre la reforma penal de 2015», Navarra, Aranzadi, 2015. ss.

83 Sentencia del Tribunal Supremo (Sala de lo Penal) núm. 427/2000, de 18 de marzo. (RJ: 2546/1998).

84 QUINTERO OLIVARES, Gonzalo (dir.). Comentario a la reforma penal de 2015. Navarra: Aranzadi, 2015. pp. 209 ss. 
Mir Puig «querer algo por la razón que sea». Ya sea la familia, uno de los contrayentes o un tercero el sujeto activo, sabe y quiere ${ }^{85}$.

Y, ¿Cabría alguna causa de justificación? Aunque es difícil apreciar causas de justificación podría alegarse un error de prohibición indirecto vencible, probando que el sujeto activo ha actuado motivado razones de fe o morales y creyendo firmemente que las mismas le amparaban,

\subsubsection{Autoría y participación}

$\mathrm{Da}$ acuerdo al art. 27 del $\mathrm{CP}$ «son responsables criminalmente de los delitos los autores y los cómplices»; y el art.28 dispone «Son autores quienes realizan el hecho por sí solos, conjuntamente o por medio de otro del que se sirven como instrumento. También serán considerados autores: a) los que inducen a otro u otros a ejecutarlo, b) los que cooperan a su ejecución con un acto sin el cual no se habría ejecutado».

Así, el autor material del delito de matrimonio forzado debe ser la persona que realice la conducta, es decir, compeler a otra a contraer matrimonio mediante violencia o intimidación.

Como ya he señalado, juega un papel muy importante en este tipo la presión del entorno familiar en la mayoría de los casos. Entiendo que los familiares son autores inmediatos del delito. Si varios sujetos actúan en régimen de coautoría, será preciso que todos ellos empleen en alguna medida los medios comisivos de la violencia o la intimidación grave con la finalidad de forzar a la víctima al matrimonio.

Respeto del futuro cónyuge si conoce la falta de consentimiento del otro cónyuge/ víctima, su participación en el delito será la de cooperador necesario, ya que su consentimiento es una condición necesaria para la ejecución del delito, pero no tiene el dominio del hecho que tiene el autor inmediato ${ }^{86}$. Igual circunstancia encontramos en la persona que oficie la ceremonia de matrimonio conociendo el consentimiento forzado de uno de los cónyuges. No obstante, si es el cónyuge quien compele a la víctima a contraer matrimonio, responderá como autor inmediato del delito ${ }^{87}$.

\subsubsection{Penas}

El Artículo 172 bis, en su apartado $1^{\circ}$, dispone «El que con intimidación grave o violencia compeliere a otra persona a contraer matrimonio será castigado con una pena

85 LUZÓN CUESTA, J.M. «Compendio de Derecho Penal» Dykinson, S.L. 2015, pp. 67 y 68.

86 Sentencia del Tribunal Supremo (Sala de lo Penal) núm. 258/2007, de 19 de julio. (RJ: 10767/2006).

87 Sentencia del Tribunal Supremo (Sala de lo Penal) núm. 258/2007, de 8 de marzo. (RJ: 10728/2009). 
de prisión de seis meses a tres años y seis meses o con multa de doce a veinticuatro meses, según la gravedad de la coacción o de los medios».

Continúa su apartado $2^{\circ}$ "La misma pena se impondrá a quien, con la finalidad de cometer los hechos a que se refiere el apartado anterior, utilice violencia, intimidación grave o engaño para forzar a otro a abandonar el territorio español o a no regresar al mismo», previendo el $3^{\circ}$ "Las penas se impondrán en su mitad superior cuando la víctima fuera menor de edad» ${ }^{88}$.

El Informe del CGPJ sobre el anteproyecto de LO 1/2015 señala que no se considera proporcionada a su gravedad la pena de multa que como alternativa se establece en el art. 172 bis CP, en atención al bien jurídico protegido en este delito y la consideración del matrimonio forzado como una figura conectada con la violencia sobre la mujer y la trata de seres ${ }^{89}$.

Según el tenor literal de este precepto requiere de intimidación grave o violencia y por tanto cuando la intimidación no sea grave se tendrá que acudir al artículo $172 \mathrm{CP}$ como tipo básico de coacciones, con casi la misma pena. Lo que puede dar lugar, según el CGPJ a supuestos que quedarán impunes.

Respecto a los tipos agravados, es claro, el mencionado en el número $3^{\circ}$, cuando la víctima fuera menor de edad, se impone la pena en su mitad superior. Dicho incremento lo considero insuficiente, ya que no resulta acorde al grado de afectación de bienes jurídicos personales de los que es titular el menor ${ }^{90}$.

Por otro lado, no se contempla la relación de parentesco entre el sujeto activo y la víctima, lo que en su caso podría dar lugar a apreciar la circunstancia mixta de parentesco del art.23 CP. Igualmente se entiende sería aplicable la agravante por razones de género del Art. 22.4 CP para aquellos casos en los que el delito se haya cometido sobre una mujer para perpetuar su rol subordinado dentro de la sociedad ${ }^{91}$.

88 España. Ley Orgánica 10/1995, de 23 de noviembre, del Código Penal. (BOE» núm. 281, de 24/11/1995).

89 Consejo General del Poder Judicial: Comisión de estudios e informes. Informe al Anteproyecto de Ley Orgánica por la que se modifica la Ley Orgánica 10/1995, de 23 de noviembre, del Código Penal, pp. 165 a 166. Disponible en: http://www.poderjudicial.es/cgpj/es/Poder-Judicial/Consejo-General-delPoder-Judicial/Actividad-del-CGPJ/Informes/Informe-al-anteproyecto-de-Ley-Organica-por-el-que-se-modifica-la-Ley-Organica-10-1995--de-23-de-noviembre--del-Codigo-Penal

90 TORRES ROSELL, N., «Matrimonio forzado: aproximación fenomenológica y análisis de los procesos de incriminación», Estudios Penales y Criminológicos, vol. XXXV, 2015, p. 900.

91 CISNEROS ÁVILA, F., «Reflexiones sobre el delito de matrimonio forzado del artículo 172 bis del CP» Diario La Ley, No 9072, 2017, Editorial Wolters Kluwer. 


\subsection{Breve referencia al tipo del Artículo 172 bis 2 y su relación con el delito de trata de seres humanos.}

El artículo 172 bis 2 castiga con la misma pena «a quien con la finalidad de cometer los hechos a los que se refiere el apartado anterior, utilice violencia, intimidación grave o engaño para forzar a otro a abandonar el territorio español o no regresar al mismo».

El hecho típico consiste en forzar a una persona a abandonar el territorio nacional o, impedirle regresar a él. Encontramos dos requisitos: que se realice con la finalidad de «cometer los hechos a que se refiere el apartado anterior» (matrimonio forzado) y, por otra, que se emplee, como medio comisivo para ese forzamiento violencia, intimidación grave, o engaño».

El término «forzar» podemos entenderlo como la fuerza o violencia para conseguir algo que habitualmente no debe ser conseguido por la fuerza, u obligar a que se ejecute algo. Siguiendo a GUINARTE CABADA entiendo que quien haya/vaya a forzar el matrimonio es la misma persona que fuerza la salida de España de la víctima o le impide el regreso ${ }^{92}$.

En la práctica es difícil deslindar y probar cuándo estamos ante violencia o intimidación. Debemos entender por intimidación una amenaza de causar o sufrir un mal inminente y grave en la persona o bienes sobre la que se proyecta; supone violencia el empleo de una fuerza física o psíquica sobre su persona. Todas estas acciones, a excepción del engaño, podían ser perseguidas a través de los delitos de coacciones y amenazas.

En cuanto a esta modalidad del engaño, la doctrina destaca que estamos ante actos preparatorios. Todavía no se ha cometido la acción, sino que se está preparando. Por lo que entienden que no debería intervenir en esa fase el Derecho Penal ${ }^{93}$. En nuestro derecho, los actos preparatorios son impunes salvo algunas excepciones.

Cabe preguntarse: ¿Por qué es merecedor de sanción penal un acto preparatorio del matrimonio forzado, el consistente en engañar a la víctima para ser trasladada al lugar donde va a ser obligada a contraer matrimonio, y no merece tal sanción penal otros actos preparatorios de otros delitos? Y por otro lado, si son sus padres los que han preparado la ceremonia, ¿necesitan recurrir al engaño para que la víctima salga del territorio nacional?

92 GUINARTE CABADA, G., «El nuevo delito de matrimonio forzado» en GONZÁLEZ CUSSAC (dir.) Comentarios a la reforma del Código Penal de 2015.Valencia: Tirant lo Blanch, 2015. p. 570.

93 SÁEZ GALLEGO, P., «El matrimonio forzado». Disponible en: «<http://www.rosapilarsaez.com/2017/ el-matrimonio-forzado $>$ 
Respecto al engaño, el artículo 37.2 del Convenio de Estambul de 2011 obliga a las partes a «adoptar las medidas legislativas o de otro tipo necesarias para tipificar como delito el hecho, cuando se cometa intencionadamente, de engañar a un adulto o a un menor para llevarlo de una Parte o de un Estado distinto a aquel en el que resida con la intención de obligarlo a contraer matrimonio». Quizás el legislador pretendía cumplir este mandato, pero la respuesta no ha sido la correcta.

Dado que en el delito de matrimonio forzado se ha optado por la mención de los tres medios comisivos, si bien en uno solo de los comportamientos típicos, de tal opción legislativa se puede deducir que este delito tiene semejanza con el delito de trata de personas, hasta el punto de que entre ambos delitos se van a plantear claros problemas concursales ${ }^{94}$.

El legislador en 2015 reconoció el matrimonio forzado como uno de los fines a los que puede ser destinada la víctima del delito de trata de seres humanos. Justificó la incorporación del matrimonio forzado en el ámbito de la trata de seres humanos invocando la Directiva 2011/26/UE, relativa a la prevención y la lucha contra la trata de seres humanos $\mathrm{y}$, más en concreto, el reconocimiento que la misma efectúa al matrimonio forzado como una de los fines a los que pueden ser destinadas las víctimas de trata. Como se ha encargado ya de poner de manifiesto la doctrina, la Directiva no obligaba al Estado español a tipificar el matrimonio forzado como modalidad de trata, puesto que el texto europeo no se refiere a este fenómeno en el articulado sino meramente entre sus considerandos. Otra cosa es, que el matrimonio forzado pueda reunir los caracteres propios del delito de trata ${ }^{95}$.

La trata de seres humanos es un delito de tendencia que requiere que las conductas alternativas señaladas en el art.177 bis CP sean ejecutadas empleando los medios, también indicados, y que se realicen con cualquiera de las finalidades enumeradas en dicho precepto ${ }^{96}$.

Por tanto, los requisitos necesarios para que exista el delito son tres, dos de carácter objetivo y uno subjetivo ${ }^{97}$.

El primero se refiere a la acción delictiva, alternativa (cualquiera de ellas da lugar al delito): «captar, transportar, trasladar, acoger, recibir e intercambiar o transferir el control sobre esas personas».

94 TRAPERO BARREALES, M.A., «Matrimonios ilegales y derecho penal. Bigamia, matrimonio inválido, matrimonio de conveniencia, matrimonio forzado y matrimonio precoz». Valencia: Tirant lo Blanch, 2016, p.

95 TORRES ROSELL, N., «Matrimonio forzado: aproximación fenomenológica y análisis de los procesos de incriminación», Estudios Penales y Criminológicos, vol. XXXV, 2015, p. 901.

96 VILLACAMPA ESTIARTE, Carolina (2012). El delito de Trata de Seres Humanos: una incriminación dictada desde el derecho internacional. Cizur Menor (Navarra), Aranzadi Thomson Reuter, p. 432.

97 Sentencia del Tribunal Supremo (Sala de lo Penal) núm. 518/2016 de 25 de noviembre. (RJ: 5587/2017) 
El segundo, exige determinados medios para cometer la anterior acción y que implican doblegar o anular la voluntad decisoria del sujeto pasivo: violencia, intimidación, engaño.... También aquí son posibilidades alternativas, cualquiera supone la comisión del delito $^{98}$.

El tercer elemento subjetivo del injusto exige una intencionalidad, exigiendo que la acción se lleve a cabo con uno de los fines que señala el propio articulo («númerus clausus») y que tienen como destino llevar a cabo el aprovechamiento de la persona, en el sentido más mercantil y cosificado de la expresión (entre ellos forzar al matrimonio). Se trata por ello de un delito «de consumación anticipada» si se comete antes de realizar dichos fines, y la comisión de éstos supone la concurrencia de otro delito añadido, cometido posteriormente (concurso real, art $73 \mathrm{CP}$ ).

Con la inclusión de la celebración de matrimonios forzados entre las finalidades relevantes de las conductas de trata, el ámbito de operatividad de la modalidad del artículo 172 bis. 2 CP (que es al que afecta) puede resultar muy escaso o prácticamente nulo.

El Informe del Consejo Fiscal al anteproyecto de LO por la que se modifica la LO 10/1995 entiende que este tipo penal puede solaparse con el artículo 177 bis CP cuando el matrimonio forzado se produce en un contexto sociológico en el que la mujer está abocada a quedar reducida a la servidumbre doméstica o sexual. Además establece que dicha conducta también se podría incardinar en el tipo agravado de coacciones del párrafo segundo del delito del artículo $172.1 \mathrm{CP}$, que establece que «cuando la coacción ejercida tuviera como objeto impedir el ejercicio de un derecho fundamental se le impondrán las penas en su mitad superior, salvo que el hecho tuviera señalada mayor pena en otro precepto de este Código». Forzar a una persona a abandonar el territorio español o a no regresar al mismo vulnera un derecho humano, en concreto el establecido en el artículo 13.2 de la Declaración Universal de Derechos Humanos de 1948, que establece que «toda persona tiene derecho a salir de cualquier país, incluso el propio y a no regresar a su país» ${ }^{99}$.

Respecto a la cuestión concursal, la propia redacción del art. 177 bis CP en su apartado 9 nos conduce hacia el concurso de delitos, al señalar que, «en todo caso, las penas previstas en este artículo se impondrán sin perjuicio de las que correspondan, en

98 Sentencia del Tribunal Supremo (Sala de lo Penal) núm. 5746/2015 de 20 de diciembre. (RJ:861/2015).

99 Consejo General del Poder Judicial: Comisión de estudios e informes. Informe al Anteproyecto de Ley Orgánica por la que se modifica la Ley Orgánica 10/1995, de 23 de noviembre, del Código Penal, pp. 142. Disponible en: http://www.poderjudicial.es/cgpj/es/Poder-Judicial/Consejo-General-del-PoderJudicial/Actividad-del-CGPJ/Informes/Informe-al-anteproyecto-de-Ley-Organica-por-el-que--semodifica-la-Ley-Organica-10-1995--de-23-de-noviembre--del-Codigo-Penal 
su caso, por los demás delitos efectivamente cometidos, incluidos los constitutivos de la correspondiente explotación» ${ }^{100}$.

Se ha interpretado mayoritariamente como indicativa del concurso real de delitos $^{101}$, si bien en este contexto resulta más acertado el concurso medial ya que la conducta del traslado constituye medio necesario para llevar a cabo el matrimonio forzado y ejecutar el tipo ${ }^{102}$. Otros autores entienden que se trata de un concurso de normas y que el delito de trata debería reservarse para aquellos supuestos más graves en que se produjera un atentado a la dignidad de un individuo.

No obstante, el art. 177 bis CP es más amplio en la determinación de los medios utilizables que el art. 172 bis CP, al incluir la intimidación no necesariamente grave, el engaño o el abuso de necesidad o vulnerabilidad; ello podría hacer que aquél se apreciara en más casos que este último. Y, además, tal art. 177 bis CP sería aplicable, y con una pena notablemente superior, también en aquellos ejemplos en que la violencia o intimidación se ejercieran, pero el matrimonio forzado no llegara a celebrarse.

La solución adoptada por el legislador en el art. 177 bis.9 CP es la de castigar en concurso los delitos de trata y de matrimonio forzado cuando se den en la práctica los elementos necesarios para apreciar ambas situaciones.

Por último, señalar, que la subsunción del matrimonio forzoso en el delito de trata de seres humanos ya era legalmente posible en el ordenamiento jurídico español, ya que la Convención suplementaria respecto de la abolición de la esclavitud, la trata de esclavos y las instituciones y prácticas análogas a la esclavitud dispone en su art.1 que todas las formas de matrimonio forzoso son definidas como prácticas análogas a la esclavitud, que reducen a uno de los cónyuges a la condición de una persona sobre la que se ejercen una parte o la totalidad de los poderes atribuidos al derecho de propiedad ${ }^{103}$. El proceso que conduce al contrayente a celebrar matrimonio forzado deberá subsumirse en el delito de trata de seres humanos si concurren los elementos exigidos en el tipo del artículo 177 bis, sin perjuicio de que, en su caso, pueda existir un concurso de delitos.

100 DE LA CUESTA AGUADO, P.M., «El delito de matrimonio forzado» en QUINTERO OLIVARES, Gonzalo (dir.). Comentario a la reforma penal de 2015. Navarra: Aranzadi, 2015. p. 372.

101 TORRES ROSELL, N., «Matrimonio forzado: aproximación fenomenológica y análisis de los procesos de incriminación», Estudios Penales y Criminológicos, vol. XXXV, 2015, pp. 1175 y 1176.

102 VILLACAMPA ESTIARTE, Carolina (2012). El delito de Trata de Seres Humanos: una incriminación dictada desde el derecho internacional. Cizur Menor (Navarra), Aranzadi Thomson Reuter, p. 456.

103 Convención suplementaria sobre la abolición de la esclavitud, la trata de esclavos y las instituciones y prácticas análogas a la esclavitud, Adoptada por una Conferencia de Plenipotenciarios convocada por el Consejo Económico y Social en su resolución 608 (XXI), de 30 de abril de 1956. Disponible en: $<\underline{\text { https:// }}$ www.ohchr.org/SP/ProfessionalInterest/Pages/SupplementaryConventionAbolitionOfSlavery.aspx $>$ 


\section{VI.- CONCLUSIONES}

Tras el análisis realizado la respuesta a si era necesaria una nueva regulación, en lo que respecta al delito de matrimonio forzado, debe ser negativa y las críticas al legislador son varias:

En primer lugar, éste hecho típico ya se podía castigar por otras vías: No era necesaria la regulación expresa sobre esta materia, la respuesta penal frente al matrimonio forzado se encuentra a través de los delitos contra la libertad: los delitos de amenazas, coacciones y delitos de detenciones ilegales (arts. 169-171.1, 172.1 y 163 CP).

La justificación ofrecida por el legislador de dar cumplimiento al mandato de la Directiva 2011/36/UE no justifica la creación de un tipo autónomo, ya que no existe una laguna de punibilidad. Como hemos visto el ordenamiento ya daba una respuesta.

Respecto a que la Directiva presente el matrimonio forzado como una forma de explotación característica del delito de trata de seres humanos, la reforma se debería haber limitado a la modificación del Art. 177 bis CP, incluyendo el matrimonio forzado entre las finalidades de la trata y no con la tipificación de ambas modalidades delictivas de forma autónoma, lo que genera problemas concursales, que no analizo de manera profunda en este artículo. No han sido pocas las cuestiones que han ido brotando.

¿Por qué el delito de matrimonio forzado? ¿Por qué no se han tipificado conductas como el traslado para la comisión de otros delitos como puede ser llevar a cabo la mutilación genital femenina?, la respuesta es la misma: estas conductas ya pueden ser perseguidas a través de los tipos previstos en el CP: En el caso de que se recurra a la coacción cabría plantear la modalidad de delito de coacciones tipificado en el art. $172.12^{\circ}$ párrafo $\mathrm{CP}$, que castiga la coacción que tiene como objeto impedir el ejercicio de un derecho fundamental, pues a través de la imposición del matrimonio el contrayente ve afectado su derecho a la autodeterminación personal y el libre desarrollo de la personalidad. Otras vías de respuesta penal, como se ha indicado las ofrece la regulación penal del delito de trata de seres humanos tipificado en el art. 177 bis o el delito de lesa humanidad del art. 607 bis.

Si generalmente la víctima del delito es menor de edad, y también generalmente son los padres los que imponen el matrimonio, como último recurso para su prevención se puede plantear alguna de las modalidades delictivas de los delitos contra las relaciones familiares

De la exposición realizada hasta ahora se puede extraer una conclusión clara: el DP vigente tiene respuesta adecuada frente a los medios más graves empleados en los matrimonios forzados. Por tanto, entiendo, estamos ante la utilización simbólica del derecho penal.

En segundo lugar, es criticable la exigencia legal de que la intimidación sea «grave» lo que dificulta la interpretación, por tratarse de un elemento puramente valorativo. 
Además, existe una consolidada jurisprudencia en torno al concepto de intimidación, que considera que la intimidación ya es grave por sí misma. La aplicación de este nuevo delito es escasa por la dificultad determinar el significado de «grave». Tampoco es correcto el término «coacción» para graduar la pena del tipo penal, ya que el mismo es ya definitorio de un tipo penal, con lo que lo más adecuado hubiera sido incorporar «según la gravedad de la violencia o intimidación ejercida».

Resulta igualmente criticable que el precepto mantenga en los supuestos de víctima menor de edad la exigencia de los medios comisivos de carácter violento o intimidatorio grave previstos en el tipo básico de matrimonio forzado, sin tomar en consideración que, en el caso de menores de edad, el propio engaño pueda bastar a los progenitores para doblegar la voluntad del menor, lo que quedaría fuera del ámbito de acción de este tipo penal, de no haber sido el menor trasladado a un tercer estado.

En tercer lugar, no es correcta la respuesta que se le ha dado en el ámbito de los delitos de violencia de género. En la situación caracterizada propiamente como violencia de género, las acciones han de ser realizadas por la pareja o expareja, pero si detrás del matrimonio forzado está el grupo familiar de uno de los contrayentes, es evidente que este supuesto queda descartado para su prevención, obviando la dimensión de género del problema.

En cuarto lugar, en lo que se refiere a la pena de multa impuesta como alternativa a la de prisión entiendo, es desacertada, ya que no es proporcionada a su gravedad atendiendo al bien jurídico protegido.

Finalmente, en quinto lugar, la tipificación del tipo autónomo de matrimonio forzado puede dar lugar al efecto contrario al perseguido con la regulación, la imposición de una menor pena al autor del delito, que, en el caso de situarlo en el ámbito del delito de detenciones ilegales, el delito de amenazas y más aún en el delito de trata de seres humanos, dando lugar al efecto punitivo privilegiante del derecho penal.

Se ha hecho un uso simbólico del Derecho Penal, conectado al fin de transmitir a la sociedad ciertos mensajes o contenidos valorativos, y su capacidad de influencia queda reducida a las mentes o las conciencias.

La forma más adecuada, entiendo, para resolver todos los conflictos planteados por los tipos que se introdujeron en el CP en 2015 pasa por optar por la punición que ya ofrecía nuestro Ordenamiento a través de las coacciones y los delitos de trata de seres humanos del Art. 177 bis del CP para evitar ese efecto privilegiado de la sanción punitiva, que entiendo no ha sido la voluntad de nuestro legislador, y, no incurrir en un cumplimiento, poco meditado, de los mandatos internacionales. 